\title{
Effect of heat-moisture treatment on resistant starch functional and thermal properties of mung bean (vigna radiate) starch
}

\begin{abstract}
The current study is focused on modification of mung bean starch which is a good source of leguminous carbohydrate for production of functional food. Combinations of Heat moisture treatment (HMT) of mung bean starch were performed at different temperature $80^{\circ}, 100^{\circ}$ and $120^{\circ} \mathrm{C}$ at moisture content $30 \%$ for time $16 \mathrm{~h}$. Resistant starch content was increased significantly after HMT. The functional properties study of native and modified mung bean starches showed that the swelling power, solubility and swelling volume of HMT starches have reduced along with increase in amylose contents of HMT starches. Changes in structures crystalline pattern through X-Ray diffraction (XRD), thermal properties (differential scanning calorimetry) and gel hardness were observed. Therefore, replacing native mung bean starch with mung bean starch obtained from heat moisture treatment promotes to the invention of innovative foods with high resistant starch levels and functional properties.
\end{abstract}

Keywords: mung bean starch, resistant starch, heat moisture treatment, thermal properties, crystalline pattern, functional properties
Volume 7 Issue 4 - 2017

\author{
Sreejani Barua, Prem Prakash Srivastav \\ Agricultural and Food Engineering Department, Indian Institute \\ of Technology, India
}

\author{
Correspondence: Sreejani Barua,Agricultural and Food \\ Engineering Department, Indian Institute of Technology, \\ Kharagpur,West Bengal 721302, India, \\ Email sreejani30।@gmail.com
}

Received: August 19, 2017 | Published: December 19, 2017
Abbreviations: RS, resistant starch; XRD, x-ray diffraction; HMT, heat moisture treatment; DSC, differential scanning calorimetry

\section{Highlights}

a. HMT treatment used for mung bean starch modification using CCRD.

b. RS level was increased in HMT starches.

c. Swelling power, swelling volume, solubility was decreased in HMT starches.

d. Increase in gelatinization temperature and decrease in melting enthalpy were noticed in HMT starches.

e. Reduction in whiteness and increment of peak intensity were perceived in HMT starches.

f. Gel hardness was found to be increased in HMT starches.

\section{Introduction}

The formulation of well-designed food products always being a very interesting sector in food science and technology. Based on the data stated by World Health Organization, ${ }^{1}$ diabetic patients have been risen from 108million in 1980 to 422million in 2014 leading to the cause of major deaths in 2030. Starch is considered as a significant carbohydrate for human regime existing due to its high source of energy. Since starch is very easily digestible in small intestine and causes increment of blood glucose level, its consumption is very much detrimental for diabetes and obsessed patients. Consequently, it is abundant task to frame food products which can imitate with fiber materials. Resistant starch (RS) is getting acceptance among several food scientists and manufacturers. ${ }^{2}$ RS, the starch fraction which is not digestible in smaller intestine and can be fermented through microflora in colon, lowering down its $\mathrm{pH}$ and prevents causes of colon cancer The valuable result of RS has been concise by several authors, which inhibits colon cancer, reduces insulin emic reaction to food, a valuable medium for the microorganisms in the intestine, preventive against formation of stones in gall bladder, controls higher cholesterol development, regulates fat accretion, and helps in assimilation ofminerals. ${ }^{3}$ Therefore RS can be an alternative approach for production of new, innovative functional food products especially for diabetes and obsessed individuals.

The manner of consumption is influenced by accessibility of grains, expediency, zone and food practices of people. ${ }^{4}$ Agriculture ministry data of India illustrates that there is a massive intensification of legume production during 1977 to 2014 from 11.97 million tons to 19.25 million tons. ${ }^{5}$ Due to unfavorable circumstances of weather the production rate minimizes to 17.19 million tons in 2015. Mung bean (Vigna radiata) is a commendatory legume produced in India and distributed to various nations of the domain due to its high production throughout country but its application is very fewer. Carbohydrate content in legumes is very high and has appreciable source of starch. A most promising part is played by mung bean in various groups of legumes in India; hence it stays essential to identify value added food using mung bean starch. Subsequently, it is needed to examine suitably modified mung bean starches which can be a substitute to ignore overly employing of most common starches in daily use. Considering the influences of food safety, security and health impacts modified mung bean starch can be utilized in the preparation of food products having essential health benefits. 
Heat-moisture treatment (HMT) is considered as one of the physical modification techniques which maintains moisture contents at a level less than $35 \%(\mathrm{~W} / \mathrm{W})$, and frequently higher temperature is provided for a definite time period. ${ }^{6}$ HMT affects many chemical properties of grains along with its digestibility. ${ }^{4} \mathrm{HMT}$, an ecologically approachable lower cost technique, is of concern to make the low Glycemic Index foods without any chemical residue. ${ }^{7}$ Significant results are reported on the HMT change of various starches i.e. canna, cassava, ${ }^{8}$ potato, ${ }^{9}$ pinhão $^{10}$ rice $^{11,12}$ and maize ${ }^{13}$ starches having major impact on the moisture levels during heat treated modification. ${ }^{6}$ Several studies have been started off on HMT of starches under different environments for enhancement of fundamental properties, most important to an increase in RS level. ${ }^{14}$ Nevertheless, it is challenging to conclude the HMT starch digestibility in a constant way as the arrangement of HMT constraints are varied, i.e., the botanic source, moisture content, temperature range, treatment time. ${ }^{15}$

The present study deals with modification of mung bean starch by heat moisture treatment (HMT) and assess the impact of HMT on the functional properties of resistant starches from Indian mung bean starch portions. As no study has been proposed on the experimental design combinations of HMT of Indian mung bean starch. This will be an unusual approach for improvement of innovative starches containing higher RS for application in food and has an immense health impact and functional properties for diabetes and obsessed patients.

\section{Materials and methods}

\section{Materials}

Mung bean (Vigna radiate) seeds were acquired from local market at IIT Kharagpur, West Bengal, India. $\alpha$-amylase from porcine pancreas (A3176-1MU,activity 16units/mg solid) and amyloglucosidase from Aspergillus niger (A7 420-25MG, activity 30-60 units/mg protein (biuret) were purchased from Sigma Chemical Company (St. Louis, MO, USA). GOD-POD, End point Assay and kinetic Assay kit was acquired from ARKRAY Healthcare Pvt. Ltd.Surat, India. Completely the chemicals and solvents used were of scientific grade.

\section{Isolation of starches}

Mung bean starch was extracted from seeds using the procedure of Shimelis et al. ${ }^{16}$ Mung beans were immered in distilled water (1:2) for $3 \mathrm{~h}$ at $4^{\circ} \mathrm{C}$ and dried through tray dryer for $3 \mathrm{~h}$ at $60^{\circ} \mathrm{C}$. It was kept for $12 \mathrm{~h}$ tempering at ambient temperature followed by dehulled using Dal Mill (Manufactured by Instruments Mfg.co calcutta). Dehulled mung beans are soaked for $30 \mathrm{~min}$ at $4^{\circ} \mathrm{C}$. It was ground to slurry using kitchen grinder mixer (TAURA CG-TD71 MIXER GRINDER, KURLA, MUMBAI) for $2 \mathrm{~min}$. The slurry was passed through 50 mesh $(297 \mu \mathrm{m})$ sieve. The screened starch slurry centrifuged at $3000 \mathrm{rpm}$ for $15 \mathrm{~min}$ and filtered using filter paper. The resulted filtered starch residues were dried in vacuum dryer (AMI Engineering) at $650 \mathrm{mmHg}, 50^{\circ} \mathrm{C}$.

\section{Heat moisture treatment}

Heat-moisture treatment (HMT) was performed according to the method described by Sui et al. ${ }^{7}$ HMT has significant effects on the yield of higher resistant starch. Starches $(20 \mathrm{~g}$, dry basis) were weighed properly and placed into glass bottles with covered tightly. Small amount of distilled water was added gently with stirring repeatedly until the moisture levels $(\mathrm{w} / \mathrm{w})$ reached at $30 \%$. After mixing thoroughly, the glass jars were made to seal tightly and kept for equilibrium condition at $4{ }^{\circ} \mathrm{C}$ for one day. Samples were heated at 80,100 and $120^{\circ} \mathrm{C}$ for $16 \mathrm{~h}$ in a hot-air oven. Finally, the samples were kept for drying at $400 \mathrm{C}$ overnight to a constant weight. Mortar and pestle was used for grinding the sample followed by passing through $400 \mu \mathrm{m}$ sieve. Depending upon the treatment temperature conditions, HMT starch samples are referred to as HMT-80, HMT-100 and HMT120.

\section{Resistant starch (RS)}

RS contents determination was done according to the analysis as provided by Englyst, Kingman \& Cummings ${ }^{17}$ with modifications. $100 \mathrm{mg}$ Starch sample was diluted in $9 \mathrm{~mL}$ phosphate buffer of $\mathrm{pH}$ 5.2 containing 4 glass beads ( $10 \mathrm{~mm}$ diameter) and $4 \mathrm{~mL}$ of solution (pancreatic a-amylase having $10 \mathrm{mg} / \mathrm{mL}$, and amyloglucosidase having $3 \mathrm{U} / \mathrm{mL}$, where $U$ means the amount of enzyme that evolves glucose of $1.00 \mathrm{mg}$ from starch in $1 \mathrm{~min}$ at $37^{\circ} \mathrm{C}$ containing $\mathrm{pH}$ 5.2) was mixed to each of the test tubes, and then kept in a quivering incubator (Test Marter testing instrument, India) for $16 \mathrm{~h}\left(370^{\circ} \mathrm{C}, 220\right.$ strokes/ min) to hydrolyze digestible starch. The portion of resistant was placed with $95 \%$ ethanol and $\mathrm{KOH}$ solution $(4 \mathrm{M}, 2 \mathrm{~mL})$ was added. Finally Samples were centrifuged (Sigma 2-16 PK) at 5000rpm for $10 \mathrm{~min}$. Glucose released from aliquots $(0.1 \mathrm{ml})$ of the supernatant was measured by GODPOD method using a spectrophotometer (Varian 50 Bio UV-visible spectrometer) at $510 \mathrm{~nm}$.

\section{Swelling power and solubility}

The swelling power and solubility of the starches were measured by the method stated by Klein et al. ${ }^{10} 50 \mathrm{~mL}$ of distilled water was mixed with $1.0 \mathrm{~g}$ of starch sample in $50 \mathrm{~mL}$ centrifuge tubes. The suspensions were heated at $900 \mathrm{C}$ for $30 \mathrm{~min}$. Then it is allowed to cool to room temperature and centrifuged at $3000 \mathrm{rpm}$ for $20 \mathrm{~min}$. The supernatant was kept for drying at $100^{\circ} \mathrm{C}$ to constant weight. The swelling power identified as the proportion of the weight of the wet residue to the weight of the initial dry sample less the quantity of soluble starch. The solubility was stated as the ratio of dried solid weight by the weight of the dry sample.

\section{Swelling volume}

The swelling volume was evaluated by using the procedure as described by Crosbie ${ }^{18}$ with some modifications. The dried starch samples $(0.5 \mathrm{~g})$ were estimated in a measuring cylinder and distilled water $(10 \mathrm{ml})$ was slowly added to it. After proper mixing, the cylinder was allowed to keep at the room temperature for $20 \mathrm{~h}$. The swelling volume was measured as the ratio of total volume of the swollen starch to the initial dry weight of the starch sample.

\section{Amylose content}

Amylose content was determined according to the procedure of Thayumanavan \& Sadasivam. ${ }^{19}$ A starch sample weighed $100.0 \pm 0.1 \mathrm{mg}$ of dry substance transferred to a $100 \mathrm{~mL}$ volumetric flask quantitatively. Ethanol of $1 \mathrm{~mL}$ was added and stirred to dissolve the starch. $10.0 \mathrm{~mL}$ of $1 \mathrm{~N}$ sodium hydroxide solution was added and again mixed with the sample. The dispersion was permitted to stand until it gets completely gelatinized. After one hour solution of $2.5 \mathrm{~mL}$ was taken and volume was ended up to $50 \mathrm{~mL}$ with distilled water. 2 drops of phenolphthalein indicator was mixed and titrated with $0.1 \mathrm{~N}$ hydrochloric acid. $2 \mathrm{~mL}$ of $0.20 \%$ iodine solution was added to dilute the volume with purified water. The solution was mixed properly and the absorbency was observed through spectrophotometer (Varian 50 Bio UV-Visible) in the range $590 \mathrm{~nm}$ 


\section{Color determination}

The color of native and modified starches was determined through Hunter Lab colorimeter. L* (whiteness), a* (redness to greenness) and $\mathrm{b}^{*}$ (yellowness to blueness) were calculated.

\section{Thermal properties}

Transition temperature of gelatinization and enthalpy were estimated for native and modified starch samples using a differential scanning calorimeter (DSC-Pyris Diamond DSC m/c; Serial No: $536 \mathrm{~N} 2040201)$. The starch sample (12mg) and distilled water $(28 \mu \mathrm{l})$ was mixed to a high-volume pan and wrapped quickly. The wrapped pans were reweighed and permitted to keep at room temperature for overnight before DSC analyses. The sample pans were allowed to be heated from 5 to $1800 \mathrm{C}$ at a heating rate of $100 \mathrm{C} / \mathrm{min}$. As a reference, a blank pan was used.

Thermal properties of native and HMT starches are shown. HMT120, HMT-100 and HMT- 80 starches showed increase in gelatinization temperature range and enthalpy than native starches.

\section{X-Ray diffraction}

X-ray patterns were observed with D/Max-2200 X-ray diffractometer (Rigaku Denki Co., Tokyo, Japan). The samples were examined within the range of $5-35^{\circ}$, maintaining target voltage $40 \mathrm{kV}$, along with current $30 \mathrm{~mA}$, and the rate of scanning was done at $8 \% \mathrm{~min}$.

\section{Gel hardness}

Gel hardness was measured by Texture Analyser (TA.XTplus, Stable Micro Systems Ltd., Godalming, UK) followed by the method described by Hormdok \& Noomhorm ${ }^{11}$ with slight modifications. $3 \mathrm{~g}$ starch sample was mixed thoroughly with $30 \mathrm{~mL}$ distilled water and allowed to formulate solid gel at $20^{\circ} \mathrm{C}$ at $48 \mathrm{~h}$. The gels were stored in small cans and sealed with parafilm for prevention of moisture losses. The gels were perforated at $1.0 \mathrm{~mm} / \mathrm{s}$ to a distance of 10.0 through cylindrical probe $(\mathrm{P} / 10,100 \mathrm{~mm}$ diameter) made by stainless steel. The height of the first peak provided the value of gel hardness.

\section{Experimental design and statistical analysis}

Logical calculations for the samples were done in triplicate, and standard deviations were described, except the results of relative crystallinities and gelatinization characteristics. All of the graphs were plotted using Origin Pro 8.0. Duncan test had been performed to verify the significance of results which was found to be statistically significant $(\mathrm{p}<0.05)$.

\section{Results and discussions \\ Resistant starch (RS) contents}

The RS content of native and heat moisture treated modified starches are calculated by the above mentioned method. RS contents in HMT starches increased significantly compared to native starch containing $6.85 \pm 0.65 \mathrm{RS}$. The RS content of native and heat moisture treated starches are given in Table 1. It has been also indicated that corn having RS levels along with pea, and lentil starches had improved from $4.6 \%, 10.0 \%$, and $9.1 \%$ to $12.3 \%, 14.5 \%, 14.7 \%$ individually after HMT. ${ }^{3}$ Li et al., ${ }^{2}$ observed the increment of different variety of mung bean (Phaseolus radiatus) resistant starch from $5.16 \pm 0.02$ to $45.15 \pm 0.06$ after treating the starch at $1200 \mathrm{C}$ at $20 \% \mathrm{MC}$ for $12 \mathrm{~h}$. The difference in result may be due to dissimilar physicochemical and functional properties of mung bean starch from different varieties. Due to the increment of RS the changes in starch molecular arrangement had been observed. Enzymatic hydrolysis rate of native and modified starch got changed due to enhancement of RS. Hydrogen bonds can be formed during HMT treatment leading to the more compactness of starch and decreased inter granular special distance. Moisture content plays a very prior role in HMT, hence moisture content was maintained at higher level in order to get the maximum yield of RS which is beneficial for health purposes as dietary functional fiber.

Table I Resistant starch, amylose content, swelling power, solubility, swelling volume and gel hardness of native and HMT starches ${ }^{a}$

\begin{tabular}{|c|c|c|c|c|c|c|}
\hline $\begin{array}{l}\text { Types of } \\
\text { Starch }^{\text {b }}\end{array}$ & $\begin{array}{l}\text { Resistant starch } \\
\text { (\%) }\end{array}$ & $\begin{array}{l}\text { Amylose } \\
\text { content (\%) }\end{array}$ & $\begin{array}{l}\text { Swelling power } \\
\text { (g/g) }\end{array}$ & $\begin{array}{l}\text { Solubility } \\
(\%)\end{array}$ & $\begin{array}{l}\text { Swelling volume } \\
(\mathrm{mL} / \mathrm{g})\end{array}$ & $\begin{array}{l}\text { Gel hardness } \\
\left(\mathrm{N} / \mathrm{m}^{2}\right)\end{array}$ \\
\hline Native starch & $6.85 \pm 0.65^{c}$ & $27.99 \pm 0.57^{d}$ & $12.46 \pm 0.15^{a}$ & $8.13 \pm 0.09^{d}$ & $2.4 \pm 0 . I^{a}$ & $158.32 \pm 0.89^{d}$ \\
\hline HМТ-80 & $32.57 \pm 0.89^{d}$ & $33.1 \pm 0.53^{\mathrm{a}}$ & $9.40 \pm 0.5 \mathrm{I}^{\mathrm{b}}$ & $5.22 \pm 0.30^{\mathrm{a}}$ & $1.36 \pm 0.15^{c}$ & $20 \mathrm{I} .77 \pm 0.5 \mathrm{I}^{\mathrm{b}}$ \\
\hline HMT-I00 & $34.42 \pm 1.18^{\mathrm{b}}$ & $31.53 \pm 0.53^{b}$ & $10.55 \pm 0.32^{b}$ & $6.36 \pm 0.33^{b}$ & $1.53 \pm 0.15^{\mathrm{bc}}$ & $310.12 \pm 0.43^{\mathrm{a}}$ \\
\hline HMT-I 20 & $38.36 \pm 1.03^{\mathrm{a}}$ & $36.16 \pm 0.72^{c}$ & $10.94 \pm 0.08^{c}$ & $6.58 \pm 0.38^{c}$ & $1.9 \pm 0.1^{c}$ & $|7| .02 \pm 0.86^{c}$ \\
\hline
\end{tabular}

aExperimental data are measured as the means of triplicate determinations \pm standard deviation. Data for resistant starch, amylose content, swelling power, solubility, swelling volume and gel hardness are denoted as significantly different $(P<0.05)$ according to the superscripts for each $\mathrm{HMT}$ conditions. bHMT, heat-moisture treatment.

\section{Swelling power and solubility}

Swelling power of native and HMT starches are presented in Table 1. Swelling power of native starch was higher than HMT starches. Amylopectin is the principal property for swelling power, whereas, amylose is considered as diluent described by Klein et al. ${ }^{10}$ In our study amylose was found to be lower in HMT starches, which means amylopectin content showed higher in native starch. So native starch showed higher swelling power than HMT starches.

There was a decrease in swelling power with increasing resistant starch content after HMT. It may be due to formation of new molecular rearrangement after HMT. This is found to be similar with the results obtained by Hormdork \& Noomhorm ${ }^{11}$ where swelling power of rice starch decreased after HMT. Moreover, similar result was established by Zavareze et al., ${ }^{12}$ for pinhao starches. Zavareze \& Dias ${ }^{20}$ stated that decrease in swelling power may be responsible for increase of amylose-amylopectin collaboration, stronger intermolecular connection, development of complexes of amylose-lipid, or can be due to alteration of the crystalline arrangement of starch.

The highest solubility was observed in native starch and found to be decreased in HMT starches (Table 1). Amylose leaching may cause enhancement of starch solubility which separates and disperses out 
during swelling. Reduction in starch solubility can be accredited to an interior reordering of granular structures of starch providing advanced collaborations between starch functional groups, the development of further orderly amylopectin bunches, and the establishment of amylose-lipid complexes within starch granules. ${ }^{20}$ Similar results were conveyed in pea, lentil and bean starches, ${ }^{21}$ rice starch, ${ }^{12}$ and yam and potato starches. ${ }^{8}$

\section{Swelling volume}

Swelling volume is an indicator of water holding capacity of the starch. All modified starches showed a decrease in swelling volume correlated to the native starch as shown in the Table 1. The swelling volume of native sweet potato starch was observed much higher than mung bean starch i.e. $32.3 \mathrm{~mL} / \mathrm{g} .{ }^{22}$ Development of double helix bonds between amylose chains, rearrangement of molecular structure and formation of resistant starch responsible for decrease in swelling volume in HMT starches. Formation of RS is a major indicator of reduced swelling volume in HMT starches.

\section{Gel hardness}

Gel hardness of native and HMT starches were shown in Table 1. The highest gel hardness was observed in HMT-100. Higher gel hardness detected in HMT starches due to lower solubility. HMT shows a very important role in increasing gel hardness due to formation of crystalline structure within starch granules. Starch retrogradation is the principle phenomenon which is governed by mainly presence of amylose than amylopectin. HMT starches exerted higher blue values which mean higher content of amylose was present in HMT starches resulted in higher gel hardness. Lower value of gel hardness in native starch can be due to presence of less crystalline structure within starch granule which leads to disruption upon increasing force. Similar result was found in pinhao starch by Zavareze et al., ${ }^{23}$ where it was explained gel hardness increased in HMT modified pinhao starches. This rise in gel hardness can be ascribed to an intensification in crosslinks between starch arrays, in specific in the amylose segment, which leads to a superior intersection zone in the amorphous stage of the gel. $^{24}$

\section{Amylose content}

The helical structure of amylose in solution is the cause of complex formation with iodine. This result revealed possible reorientation and formation of amylose structures in the non-crystalline sections of starch.

The difference in amylose content between native and HMT starch was found to be relevant and shown in Table 1. The amylose content of HMT-120 was highest of all modified and native starch samples. The increase in amylose content leads to the collaboration between starch helical within the amorphous zone of the granule. The effect of interaction between amylose contents showed highest in HMT-3 starches. Increase in amylose after HMT can replicate the connotation of amylose-amylose, amylose-amylopectin molecules. ${ }^{8}$ The increase in blue values in HMT starches signifies more amylose content which leads to formation of new amylose-amylose, amylose-amylopectin bonds formation within amorphous regions of starch granules.

\section{Color}

$\mathrm{L}^{*}, \mathrm{a}^{*}$ and $\mathrm{b}^{*}$ values recorded for native and modified starches of mung bean were listed in Table 1. The significant difference in whiteness index was observed in native and modified starches. Due to HMT decrease in $L^{*}$ value and increase in $a^{*}, b^{*}$ values were observed. The change of color may be due to caramalization reaction occurs during HMT which produces simple sugars by breaking down starch molecules. Higher whiteness values of starch is preferred for consumer acceptance (Table 2).

Table 2 Color values of native and HMT starches ${ }^{\mathrm{a}}$

\begin{tabular}{llll}
\hline Type of starch & $\mathbf{L}^{*} \mathbf{b}$ & $\mathbf{a}^{*} \mathbf{c}$ & $\mathbf{b}^{*} \mathbf{d}$ \\
\hline Native Starch & $95.45 \pm 0.85^{\mathrm{a}}$ & $-0.63 \pm 0.0 \mathrm{I}^{\mathrm{c}}$ & $7.97 \pm 0.06^{\mathrm{d}}$ \\
HMT-I & $87.68 \pm 0.07^{\mathrm{b}}$ & $2.16 \pm 0.03^{\mathrm{a}}$ & $15 \pm 0.07^{\mathrm{b}}$ \\
HMT-2 & $84.63 \pm 0.45^{\mathrm{c}}$ & $1.73 \pm 0.55^{\mathrm{b}}$ & $16.74 \pm 0.04^{\mathrm{a}}$ \\
HMT-3 & $83.66 \pm 0.15^{\mathrm{d}}$ & $2.1 \pm 0 . \mathrm{I}^{\mathrm{ab}}$ & $14.24 \pm 0.0 \mathrm{I}^{\mathrm{c}}$ \\
\hline
\end{tabular}

a Color values of starches were determined as the means of triplicates values \pm standard deviations. Values of color are found to be significantly different $(P<0.05)$ according to the superscripts for each HMT treatment.

$b, c, d *$, whiteness value; $a^{*}$, redness to greenness; $b^{*}$, yellowness to blueness.

\section{Thermal properties}

Thermal properties of native and modified starches had been shown in Figure 1. Native starch showed the lowest gelatinization temperature Native mung bean starch had a transition temperature ranging from $106.79^{\circ} \mathrm{C}$ to $109.680 \mathrm{C}$ with enthalpy of $55.60 \mathrm{~J} / \mathrm{g}$ (dry sample). Results clearly reveals that HMT-120, HMT-100 and HMT80 starches had a gelatinization temperature range of $138.64^{\circ} \mathrm{C}$ to $140.44^{\circ} \mathrm{C}, 114.43^{\circ} \mathrm{C}$ to $126.45^{\circ} \mathrm{C}$ and $109.35^{\circ} \mathrm{C}$ to $123.59^{\circ} \mathrm{C}$ respectively. The melting enthalpy for HMT starches were about $55.69 \mathrm{~J} / \mathrm{g}$ to $47.52,63.89$ and $60.90 \mathrm{~J} / \mathrm{g}$ native for HMT-120, HMT100 and HMT-80 respectively. These difference in gelatinization temperature diverse due to amylose content, the size, dispersion of granular structures, and finally to the re-alignment of starch helices within the granule. Molecular architecture of the crystalline region played a very significant role in changing of transition temperatures..$^{25}$ HMT enhanced the associations between starch chain within the amorphous regions and order of crystallinities. ${ }^{8}$ Higher range of gelatinization temperature implies that more heat is required to break down the crystalline orientation after HMT.

Increase in melting enthalpy can be due formation of compact structure and increment of molecular integrity after HMT. Disruption of double helices exists in the crystalline and non-crystalline sections of the granules responsible for reduction of melting enthalpy in HMT120. Higher RS formation may cause interference in double helical structures leading to partial gelatinization within amorphous phase of starch granules.

\section{X-ray diffraction}

The X-ray diffractograms of native and modified mung bean starches are presented in Figure 2. Native mung bean starch showed

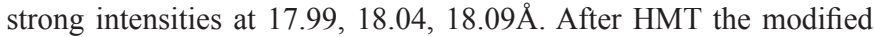
starches revealed strong diffraction intensity relatively at the peak of $17.14,17.24$ and $17.84 \AA$ respectively. The intensities of the peak was found to be significantly higher in HMT starches at $23.0 \AA$. Native starch showed 'A' type characteristic pattern which remained unchanged after HMT. The result showed that moisture content played 
a very important Zavareze \& Dias $^{23}$ explained that the relocation of double helices within starch crystals is responsible for the increase of $\mathrm{X}$-ray intensity. Structural rearrangement within starch granules may increase intensities of diffraction peaks, where displacement of double helices between starch crystals occurred moisture and thermal energy provided in HMT and leaded to the development of a better packed and orderly crystalline arrangement than those from native starches. ${ }^{15}$ The decrease in the X-ray peak intensity observed in rice and cassava starches suggests a loss of the crystallinity due to displacement of the nearby double helices and the reorganization of alignments in a dissimilar way. ${ }^{26}$

Several authors reported an increase in the intensity of the X-ray diffraction of $\operatorname{corn}^{27}$ and sweet potato starches ${ }^{28}$ after HMT. Overall no change in granule morphology was observed after HMT and this result was similar for wheat, oat, lentil, potato, finger millet, and yam starches found by several authors. ${ }^{6,27,29-31}$

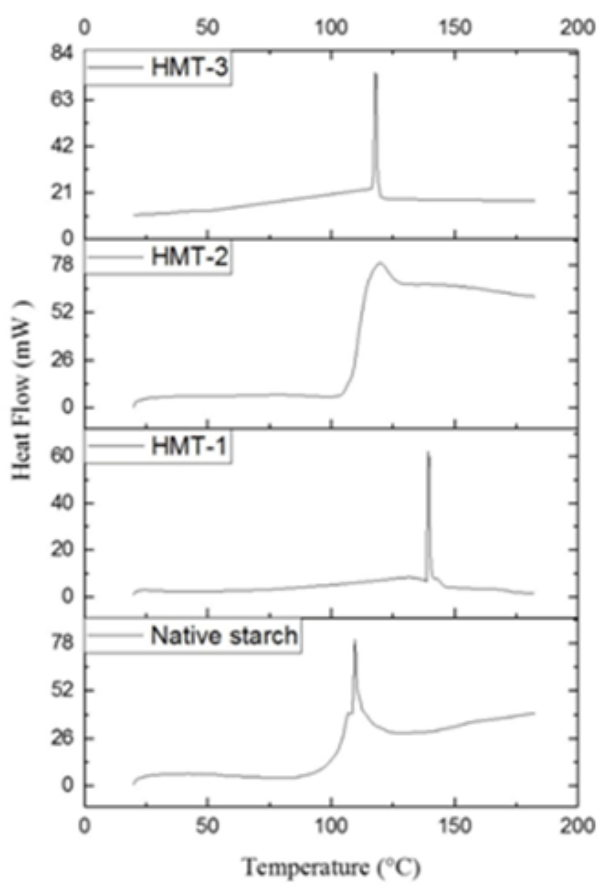

Figure I Thermal properties of Native and HMT modified starches.

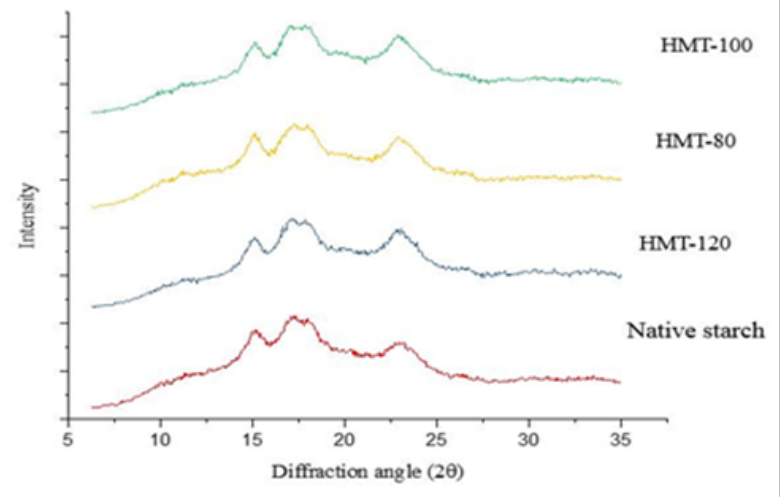

Figure 2 X-Ray diffraction pattern of Native and HMT starches.

\section{Conclusion}

HMT promotes alterations in functional properties of resistant starch levels, swelling power and solubility, swelling volume, amylose content. Sharp increase in peak intensity in X ray diffraction along with gel hardness was observed in HMT starches. HMT-120 helped in increasing highest RS level from $6.85 \pm 0.65$ to $38.36 \pm 1.03$ $\%$. Increase in gelatinization temperature and enthalpy was identified in HMT starches due to crystalline structure formation after treatment which needs more energy and higher temperature to dissociate starch structures. Whereas, higher RS for formation leads to reduce melting enthalpy followed by formation of disintegration in helical structures in amorphous regions. Apart from other modification treatments HMT performs a very important role due to its cost effectiveness. HMT can enhance resistant starch levels in a magnificent way which will further enhance the health aspects of functional food products. Moreover, more studies are required on molecular level on changes in helical structures, absorption of water molecules, zone of amylose and amylose-amylopectin conformation before and after HMT.

The starch subjected to heat moisture treatment was found to be relevant to food applications due to lower swelling power, solubility, swelling volume and higher thermal stability, whereas increased amount of RS level in HMT starches signifies as enhanced in functional fiber with all healthier aspects.

\section{Acknowledgements}

The author thank department of Agricultural and Food Engineering, IIT Kharagpur, West Bengal, India for financial support to carry out this present research work.

\section{Conflict of interest}

The author declares no conflict of interest.

\section{References}

1. Global report on diabetes. Europe: World Health Organization; 2016.

2. Li S, Ward R, Gao Q. Effect of heat-moisture treatment on the formation and physicochemical properties of resistant starch from mung bean (Phaseolus radiatus) starch. Food Hydrocolloids. 2011;25(7):17021709.

3. Chung HJ, Liu Q, Hoover R. Impact of annealing and heat-moisture treatment on rapidly digestible, slowly digestible and resistant starch levels in native and gelatinized corn, pea and lentil starches. Carbohydrate Polymers. 2009;75(3):436-447.

4. Srivastav PP, Das H, Prasad S. Effect of roasting process variables on in-vitro protein digestibility of Bengalgram, maize and soybean. Food chemistry. 1990;35(1):31-37.

5. Anonymous. Agricultural statistics at a glance 2014, Ministry of Agriculture, Government of India; 2015. p. 102-103.

6. Jacobs H, Delcour JA. Hydrothermal modifications of granular starch, with retention of the granular structure: A review. Journal of agricultural and food chemistry. 1998;46(8):2895-2905.

7. Sui Z, Yao T, Zhao Y, et al. Effects of heat-moisture treatment reaction conditions on the physicochemical and structural properties of maize starch: Moisture and length of heating. Food chemistry. 2015;173:11251132.

8. Gunaratne A, Hoover R. Effect of heat-moisture treatment on the structure and physicochemical properties of tuber and root starches. Carbohydrate Polymers. 2002;49(4):425-437. 
9. Vermeylen R, Goderis B, Delcour JA. An X-ray study of hydrothermally treated potato starch. Carbohydrate Polymers. 2006;64(2):364-375.

10. Klein B, Pinto VZ, Vanier NL, et al. Effect of single and dual heatmoisture treatments on properties of rice, cassava, and pinhao starches. Carbohydrate polymers. 2013;98(2):1578-1584.

11. Hormdok R, Noomhorm A. Hydrothermal treatments of rice starch for improvement of rice noodle quality. LWT-Food Science and Technology. 2007;40(10):1723-1731.

12. da Rosa Zavareze E, Storck CR, de Castro LAS, et al. Effect of heatmoisture treatment on rice starch of varying amylose content. Food Chemistry. 2010;121(2):358-365.

13. Miyazaki M, Morita N. Effect of heat-moisture treated maize starch on the properties of dough and bread. Food Research International. 2005;38(4):369-376.

14. J He, J Liu, G Zhang. Slowly digestible waxy maize starch prepared by octenylsuccinic anhydride esterification and heat- moisture treatment: glycemic response and mechanism. Biomacromolecules. 2007;9(1):175184.

15. Hoover R. The impact of heat-moisture treatment on molecular structures and properties of starches isolated from different botanical sources. Crit Rev Food Sci Nutr. 2010;50(9):835-847.

16. Shimelis EA, Meaza M, Rakshit SK. Physico-chemical properties, pasting behavior and functional characteristics of flours and starches from improved bean (Phaseolus vulgaris L.) varieties grown in East Africa. Agricultural Engineering International: CIGR Journal. 2006:8.

17. Englyst HN, Kingman SM, Cummings JH. Classification and measurement of nutritionally important starch fractions. Eur J Clin Nutr. 1992;46(Suppl 2):S33-S50.

18. Crosbie GB. The relationship between starch swelling properties, paste viscosity and boiled noodle quality in wheat flours. Journal of cereal science. 1991;13(2):145-150.

19. Thayumanavan B, Sadasivam S. Physicohemical basis for the preferential uses of certain rice varieties. Plant Foods for Human Nutrition. 1984;34(4):253-259.

20. da Rosa Zavareze E, Dias ARG. Impact of heat-moisture treatment and annealing in starches: A review. Carbohydrate Polymers. 2011;83(2):317-328.
21. Chung YL, Ansari S, Estevez L, et al. Preparation and properties of biodegradable starch-clay nanocomposites. Carbohydrate Polymers. 2010;79(2):391-396

22. Collado LS, Corke H. Heat-moisture treatment effects on sweetpotato starches differing in amylose content. Food chemistry. 1999;65(3):339346.

23. da Rosa Zavareze E, Pinto VZ, Klein B, et al. Development of oxidised and heat-moisture treated potato starch film. Food chemistry. 2012;132(1):344-350

24. Liu H, Corke H, Ramsden L. The effect of autoclaving on the acetylation of ae, wx, and normal maize starches. Stärke. 2000;52(10):353-360.

25. Miao M, Jiang B, Zhang $T$. Effect of pullulanase debranching and recrystallization on structure and digestibility of waxy maize starch. Carbohydrate Polymers. 2009;76(2):214-221.

26. Hoover R, Vasanthan T. Effect of heat-moisture treatment on the structure and physicochemical properties of cereal, legume, and tuber starches. Carbohydr Res. 1994;252:33-53.

27. Hoover R, Manuel H. Effect of heat-moisture treatment on the structure and physicochemical properties of legume starches. Food Research International. 1996;29(8):731-750.

28. Vieira FC, Sarmento S. Heat-Moisture Treatment and Enzymatic Digestibility of Peruvian Carrot, Sweet Potato and Ginger Starches. Starch-Stärke. 2008;60(5):223-232.

29. Adebowale KO, Afolabi TA, Olu-Owolabi BI. Hydrothermal treatments of Finger millet (Eleusine coracana) starch. Food Hydrocolloids. 2005;19(6):974-983

30. Jayakody L, Hoover R, Liu Q, et al. Studies on tuber starches III. Impact of annealing on the molecular structure, composition and physicochemical properties of yam (Dioscoreasp.) starches grown in Sri Lanka. Carbohydrate Polymers. 2009;76(1):145-153.

31. Stute R. Hydrothermal Modification of Starches: The Difference between Annealing and Heat/Moisture-Treatment. Starch-Stärke. 1992;44(6):205-214. 